\title{
Tools and resources for neuroanatomy education: a systematic review
}

\author{
M. Arantes ${ }^{1,2^{*}}$, J. Arantes $^{3}$ and M. A. Ferreira ${ }^{4}$
}

\begin{abstract}
Background: The aim of this review was to identify studies exploring neuroanatomy teaching tools and their impact in learning, as a basis towards the implementation of a neuroanatomy program in the context of a curricular reform in medical education.

Methods: Computer-assisted searches were conducted through March 2017 in the PubMed, Web of Science, Medline, Current Contents Connect, $\mathrm{KCl}$ and Scielo Citation Index databases. Four sets of keywords were used, combining "neuroanatomy" with "education", "teaching", "learning" and "student*". Studies were reviewed independently by two readers, and data collected were confirmed by a third reader.
\end{abstract}

Results: Of the 214 studies identified, 29 studies reported data on the impact of using specific neuroanatomy teaching tools. Most of them (83\%) were published in the last 8 years and were conducted in the United States of America (65.52\%). Regarding the participants, medical students were the most studied sample (37.93\%) and the majority of the studies (65.52\%) had less than 100 participants. Approximately half of the studies included in this review used digital teaching tools (e.g., 3D computer neuroanatomy models), whereas the remaining used non-digital learning tools (e.g., 3D physical models).

Conclusions: Our work highlight the progressive interest in the study of neuroanatomy teaching tools over the last years, as evidenced from the number of publications and highlight the need to consider new tools, coping with technological development in medical education.

Keywords: Neuroanatomy, Education, Teaching, Learning, Student

\section{Background}

Among the basic sciences providing relevant medical awareness, human anatomy, which includes gross and neuroanatomy, has historically been considered a key science educational area in medical education $[1,2]$.

The first descriptions of human anatomy teaching in Europe dates back to Greece, in third century BC, with the introduction of systemic human cadaveric dissection. Although the practice of human dissection was prohibited during the Middle Ages due to religious and popular beliefs, it revival at the beginning of fourteenth century and becomes the core basis in medical education and anatomy teaching until the twentieth century

\footnotetext{
* Correspondence: mavildearantes@hotmail.com

'Department of Biomedicine, Unit of Anatomy, Faculty of Medicine of the University of Porto, Al. Prof. Hernâni Monteiro, 4200 - 319, Porto, Portugal ${ }^{2}$ Division of Neuroradiology, Department of Radiology, Portuguese Institute of Oncology, Porto, Portugal

Full list of author information is available at the end of the article
}

$[3,4]$. By that time, significant changes have occurred in undergraduate medical education, on one hand because of the introduction of new subjects into curricular programmes as medical scientific knowledge increases and on the other hand because of the move towards skillsbased teaching to face clinical practice [5-8]. Within this new reality, many preclinical medical curricula started to integrate systems-based units, abandoning the traditional, isolated, discipline-based curricular approaches [9-14].

These changing concepts greatly influenced the modern teaching of medical anatomy, with many schools now delivering anatomy using integrated, clinicallyoriented modules, with considerably less time allocated to anatomy [15-17]. For example, within the USA contact hours for gross anatomy has fallen from an average of $170 \mathrm{~h}$ in 2002 to $\sim 150 \mathrm{~h}$ in 2012 and in neuroanatomy contact hours decreased from 95 to $83 \mathrm{~h}$ from 2002 
to 2012 [18]. This general reduction in time dedicated to anatomy teaching at medical schools, associated with the increased demand for clinical importance of the topics covered in anatomy curricula, have led to a redefinition of program content and students' learning objectives, accompanied by the introduction of innovative teaching and learning approaches. Despite the long history, the role of cadaveric dissection, as the primary tool for anatomical teaching, has been reduced or replaced in most medical schools by prosection, use of plastic models and/or multimedia-based learning packages [19].

Although initially integrated with the teaching of gross anatomy, neuroanatomy can now be found as a stand-alone course or, most frequently, as an integrated part of the systems-based approach, taught alongside other neurosciences. Teaching of neuroanatomy to students is known to be particularly challenging, due to the sheer complexity and interconnectedness of the central nervous system [20]. Students are required to learn not only anatomical structures, but also be able to understand their topography, spatial relationships and clinical significance. In 1994, Jozefowicz [21] introduced the term "neurophobia" as "a fear of the neural sciences and clinical neurology that is due to the students' inability to apply their knowledge of basic sciences to clinical situations". In fact, poor teaching and the challenging nature of aspects of neuroanatomy were identified, in one study, as reasons for considering neurosciences/ neurology so difficult. To face changes in medical education curricula and to help reduce neurophobia, some anatomists have developed and implemented innovative teaching techniques and strategies. In this context, Moxham et al. [22] also proposed a core syllabus for teaching neuroanatomy to medical students, to provide guidelines concerning neuroanatomical knowledge. However, the debate over how best to teach neuroanatomy in undergraduate medical education continues, with each institution using its own method.

The major aim of the present work is to review the most common methods for teaching neuroanatomy, and their effectiveness. More specifically, we intend to: a) identify the studies that explore neuroanatomy teaching tools; and b) to assess their impact on learning.

\section{Methods}

\section{Databases searched and search terms}

The electronic databases searched in this review included those identified as the most relevant to the topic. More specifically, computer-assisted searches were conducted in six online databases: PubMed, Web of Science, Medline, Current Contents Connect, $\mathrm{KCI}$ and Scielo Citation Index. As keywords, four sets were used, combining "neuroanatomy" with "education", "teaching", "learning" and "student"".

\section{Inclusion and exclusion criteria}

The search was restricted to English-language studies that focus on the teaching of neuroanatomy. A comprehensive search was performed for papers available for search from each database's inception through March 2017. Papers available online ahead of the print version were also analyzed. Manuscripts were included if they were original research studies assessing the impact of using a specific method on student's learning of neuroanatomy.

The exclusion criteria were as follows: i) descriptive studies on the use of a teaching method without assessing the impact on learning; ii) studies describing the development of a teaching method; iii) studies not focused on the teaching of human neuroanatomy; iv) studies in languages other than English; v) reviews, editorial material, proceeding papers, notes, letters to the Editors and meeting abstracts; and vi) duplicate papers.

\section{Selection of papers}

All databased were reviewed independently by two readers (M.A. and J.A.) using the above stated criteria. More specifically, each manuscript identified was placed on an Excel spreadsheet, and the readers applied the exclusion criteria independently. Disagreements were discussed in a meeting and resolved by consensus. After removal of duplicate manuscripts, all potentially eligible manuscripts were screened by both readers. Then, the full text of all screened manuscripts was carefully read. All data collected was confirmed by a third reader (M.F.), and discussions occurred until a final consensus was reached.

\section{Charting collating and summarizing the data}

Spreadsheets were used to register the most important features of each study, namely the title of the papers, authors, year of publication, university and country where the study was conducted, type and number of participants, teaching tool, aim, methodology, number of participants, and main results/conclusions. Data were summarized, and were then grouped according to these features.

\section{Results}

\section{Studies included in this review}

The search of PubMed, Web of Science, Medline, Current Contents Connect, KCI and Scielo Citation Index databased yielded 214 manuscripts. After removal of duplicate studies $(n=92)$, a total of 122 manuscripts were identified. On applying the inclusion and exclusion criteria by the two independent readers, 53 manuscripts were excluded because they were written in languages other than English, were abstracts, letters to the Editors, editorial material, proceeding papers, or notes. Therefore, a total of 69 manuscripts were then assessed for eligibility. After these manuscripts were read in their 
entirety, 40 studies were excluded because they were descriptive reports of a teaching method without assessing its effectiveness, they described the development of a new teaching tool, did not focused on the learning of neuroanatomy (e.g., neuroanatomy of schizophrenic patients) or were review manuscripts. Thus, a total of 29 manuscripts meet the criteria to be included in this review (see Fig. 1).

Table 1 presents some of the features of the papers included in the present work. Of the 29 studies, the first study [36] was published 50 years ago, in 1966. However, the majority of the studies $(n=15 ; 52 \%)$ were published in 2012-2016, and $24(83 \%)$ of the studies found were published in the last 8 years. Only 4 (14\%) were published before 2005. Most studies were conducted in the United States of America $(n=19 ; 65.52 \%)$, followed by the United Kingdom $(n=4 ; 13.79 \%)$ and Australia $(n=2$; $6.90 \%)$. The remaining four studies were from Canada, India, Poland and Spain.

Regarding the type of participants, medical students are the most studied sample $(n=11 ; 37.93 \%)$, followed by psychology students $(n=4 ; 13.79 \%)$, non-specified undergraduate students with neuroanatomy experience $(n=4 ; 13.79 \%)$, biology students $(n=3 ; 10.34 \%)$, psysical/occupational therapy students $(n=3 ; 10.34 \%)$, and volunteers without neuroanatomy experience $(n=3 ; 10$. $34 \%)$. Only one study (3.45\%) investigated the effect of a neuroanatomy teaching tool on faculty members. Although 10 studies $(34.48 \%)$ had 100 or more participants, the remaining $19(65.52 \%)$ had a number of participants less than 100 . One study only presented 13 students as participants.
The teaching methods used in the studies included in this review can be classified into digital tools $(n=13 ; 46$. $43 \%)$ and non-digital learning tools $(n=15 ; 53.57 \%)$. The digital tools include 3D computer neuroanatomy models, computer-based tools (i.e., computer-aided instruction/ learning), and apps installed in tablets. The non-digital tools include the use of case studies, equivalence-based instruction (EBI), 3D physical models, face-to-face teaching, flipped classroom, inquiry-based laboratory instruction, intensive mode of delivery, interpolation of questions, near-peer teaching, Renaissance artists' depictions, selfinstructional stations, and truncated lectures, conceptual exercises and manipulatives.

\section{Digital tools}

\section{Computer-based neuroanatomy tools}

Table 2 summarizes each study included in this review, including the teaching tool used, aims, methodology employed, and main results/conclusion. Some researchers [23-28] focused their studies on the impact of using computer-based tools for teaching neuroanatomy. More specifically, McKeough et al. [23, 24] investigated the effect of a computer-based tool on students' performance and their attitudes. Before and after test questions revealed that scores improved significantly after working with the learning model. In addition, students reported the computer-aided neuroanatomy learning modules as a valuable and enjoyable learning tool, and perceived their clinical-self efficacy as higher as a result of working with them.

Foreman et al. [25] conducted a prospective evaluation by asking questions to the students regarding tool

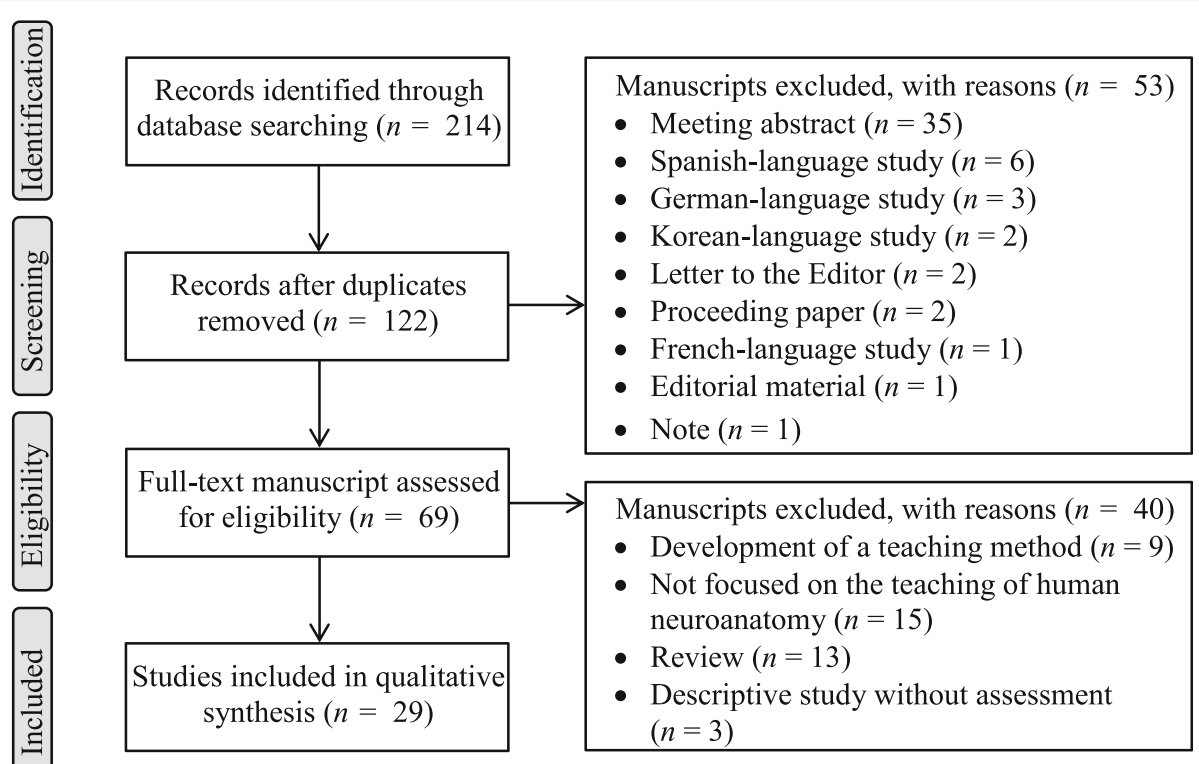

Fig. 1 Process applied to identify the manuscripts 
Table 1 Main features of the manuscripts included in this review $(n=29)$

\begin{tabular}{|c|c|c|}
\hline Features & Number (\%) & Studies \\
\hline \multicolumn{3}{|l|}{ Publication year } \\
\hline $2012-2016$ & $15(51.72)$ & I, II, III, IV, V, VI, VIII, VIII, IX, X, XI, XII, XIII, XIV, XV \\
\hline $2007-2011$ & $9(31.03)$ & $X V I, X V I I, X V I I I, X I X, X X, X X I, X X I I, X X I I I, X X I V$ \\
\hline 2002-2007 & $1(3.45)$ & $X X V$ \\
\hline $1966-2001$ & $4(13.79)$ & $X X V I, X X V I I, X X V I I I, X X I X$ \\
\hline \multicolumn{3}{|l|}{ Place of the study } \\
\hline $\begin{array}{l}\text { Australia } \\
\text { Canada } \\
\text { India } \\
\text { Poland } \\
\text { Spain } \\
\text { UK } \\
\text { USA }\end{array}$ & $\begin{array}{l}2(6.90) \\
1(3.45) \\
1(3.45) \\
1(3.45) \\
1(3.45) \\
4(13.79) \\
19(65.52)\end{array}$ & $\begin{array}{l}X I, X I I I \\
I \\
V \\
X V I I I \\
V I I I \\
\|, I I I, X I I, X X I I I \\
I V, V I, V I I, I X, X, X I V, X V, X V I, X V I I, X I X, X X, X X I, X X I I, X X I V, X X V \\
X X V I, X X V I I, X X V I I I, X X I X\end{array}$ \\
\hline \multicolumn{3}{|l|}{ Type of participants } \\
\hline Faculty members and students & $1(3.45)$ & $X X I I$ \\
\hline Master's degree health care professional students & $1(3.45)$ & $X X I$ \\
\hline Non-specified undergraduate students with neuroanatomy experience & $4(13.79)$ & $\mathrm{VI}, \mathrm{VIII}, \mathrm{XI}, \mathrm{XIII}$ \\
\hline Participants without neuroanatomy experience & $3(10.34)$ & VIII, IX, XVI \\
\hline Undergraduate or graduate biology students & $3(10.34)$ & $X I V, X V I I, X X I V$ \\
\hline Undergraduate biomedical students & $1(3.45)$ & $\|$ \\
\hline Undergraduate medical students & $11(37.93)$ & I, III, IV, V, XII, XVIII, XX, XXIII, XXVII, XXVIII, XXIX \\
\hline Undergraduate psychology students & $4(13.79)$ & $X, X I V, X V, X X V I$ \\
\hline Undergraduate or graduate physical/ocupational therapy students & $3(10.35)$ & XIX, XXIV, XXV \\
\hline \multicolumn{3}{|l|}{ Number of participants } \\
\hline+201 & $3(10.35)$ & $\|, X V I I I, X X I\|$ \\
\hline $151-200$ & $3(10.35)$ & $X I I I, X X V I I, X X V I I I$ \\
\hline $101-150$ & $4(13.79)$ & $V, X I, X X, X X I X$ \\
\hline $51-100$ & $11(37.93)$ & $I V, V I, V I I, V I I I, I X, X I I, X V, X V I, X I X, X X I, X X I I$ \\
\hline $0-50$ & $8(27.59)$ & I, III, X, XIV, XVII, XXIV, XXV, XXVI \\
\hline \multicolumn{3}{|l|}{ Teaching tool } \\
\hline Digital tool & $14(50.00)$ & I, II, IV, VII, VIII, IX, XVI, XIX, XX, XXI, XXII, XXIII, XXV, XXVII \\
\hline Non-digital tool & $14(50.00)$ & $I I I, V, V I, X, X I, X I I, X I I I, X I V, X V, X V I I, X X I V, X X V I, X X V I I I, X X I X$ \\
\hline \multicolumn{3}{|l|}{ Type of teaching tool } \\
\hline $\begin{array}{l}\text { 3D computer neuroanatomy tools } \\
\text { 3D physical models } \\
\text { Apps installed in tablets } \\
\text { Case studies } \\
\text { Computer-based neuroanatomy tools } \\
\text { Equivalence-based instruction, EBI } \\
\text { Face-to-face teaching } \\
\text { Flipped classroom } \\
\text { Inquiry-based laboratory instruction } \\
\text { Intensive mode of delivery } \\
\text { Interpolation of questions } \\
\text { Near-peer teaching } \\
\text { Renaissance artists' depictions } \\
\text { Self-instructional stations } \\
\text { Truncated lectures, conceptual exercises and manipulatives }\end{array}$ & $\begin{array}{ll}6 & (21.43) \\
1 & (3.57) \\
1 & (3.57) \\
3 & (10.71) \\
6 & (21.43) \\
2 & (7.14) \\
1 & (3.57) \\
1 & (3.57) \\
1 & (3.57) \\
1 & (3.57) \\
1 & (3.57) \\
1 & (3.57) \\
1 & (3.57) \\
1 & (3.57) \\
1 & (3.57)\end{array}$ & $\begin{array}{l}I, I V, V I I, V I I I, I X, X V I, \\
X X \\
\| \\
X I V \\
X I X, X X I, X X I I, X X I I I, X X V, X X V I I \\
\| I I, X V \\
X I I I \\
V \\
V I \\
X I \\
X X I X \\
X I I \\
X \\
X X V I I I \\
X X I V\end{array}$ \\
\hline
\end{tabular}




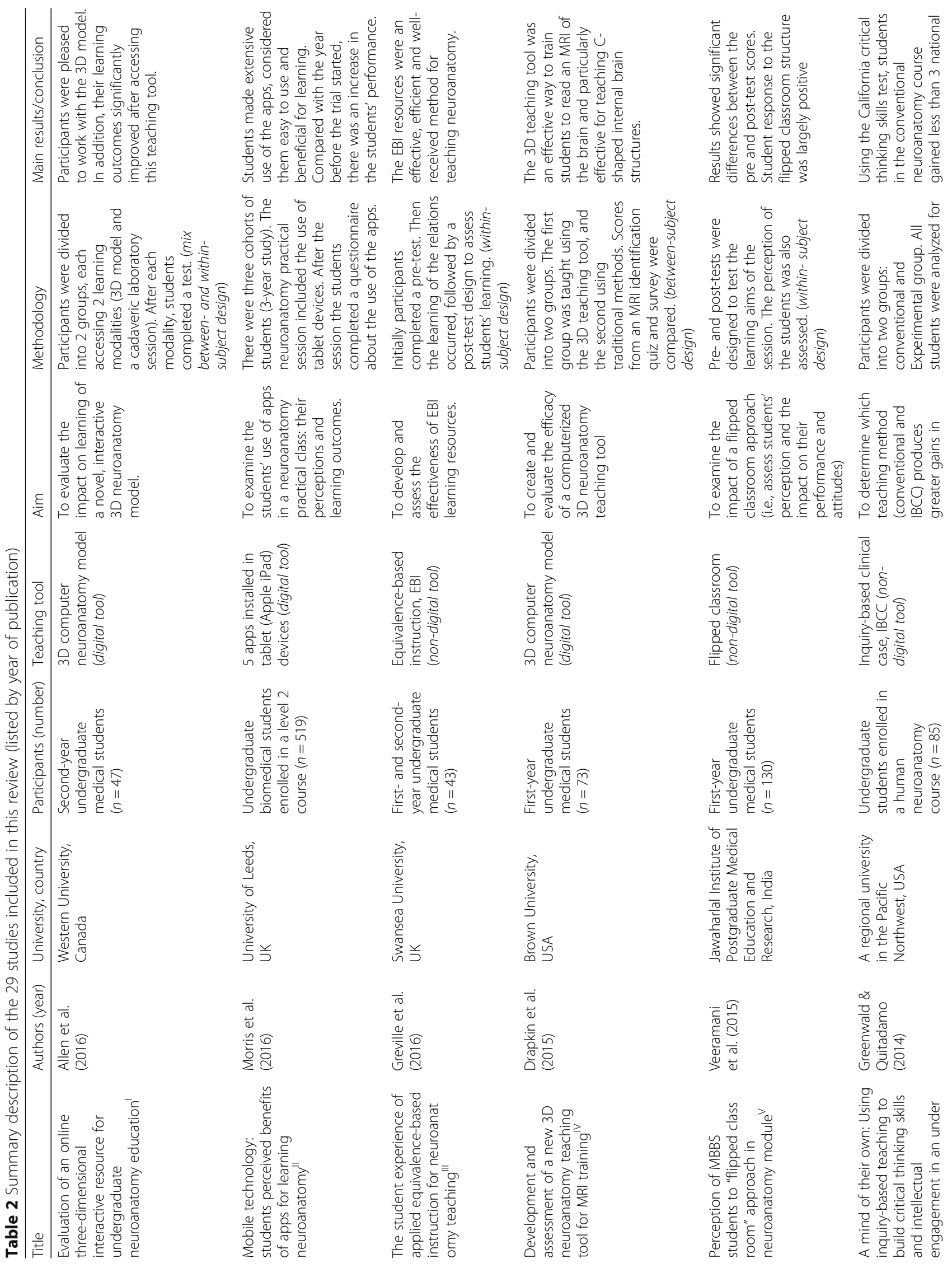




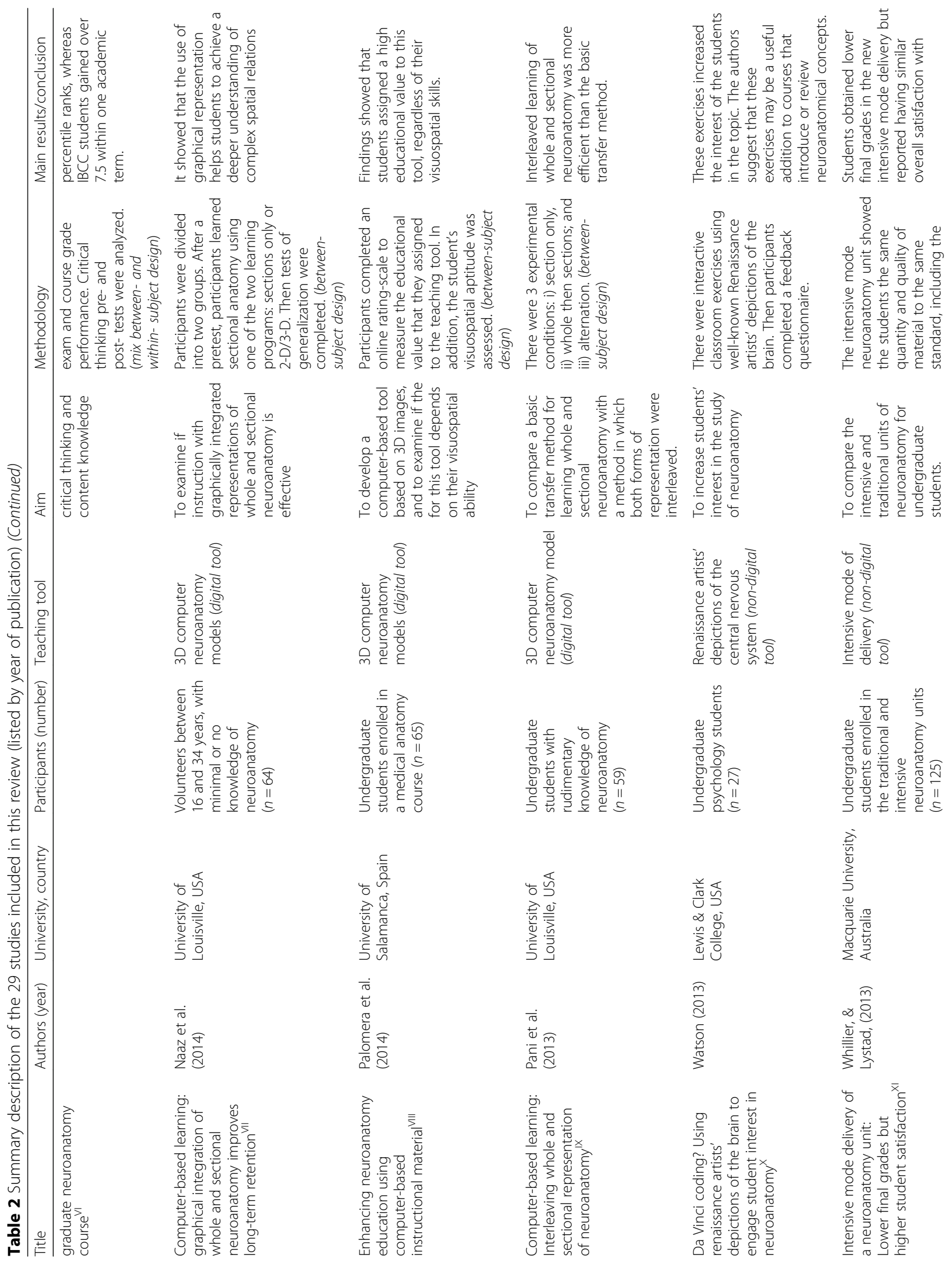




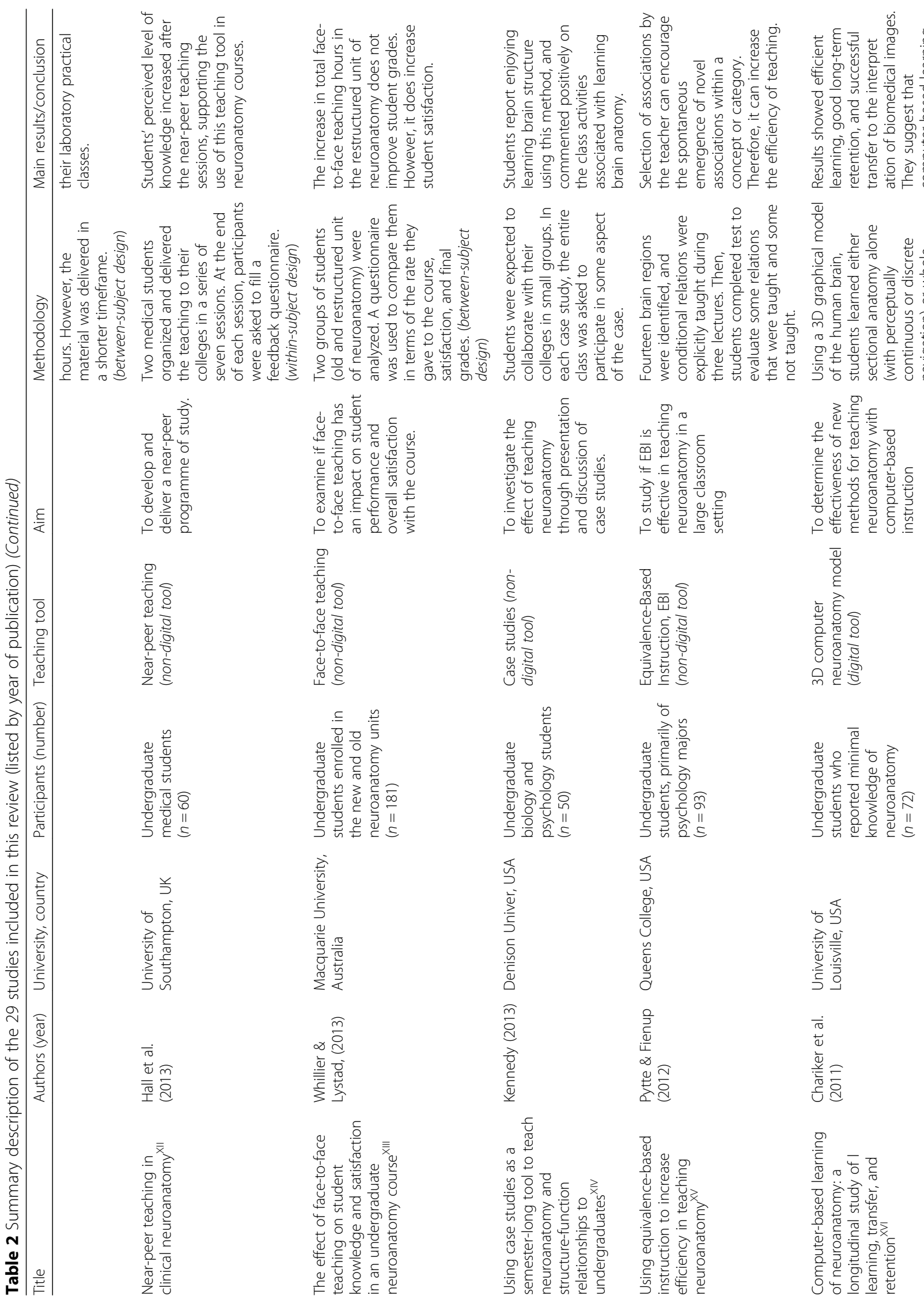




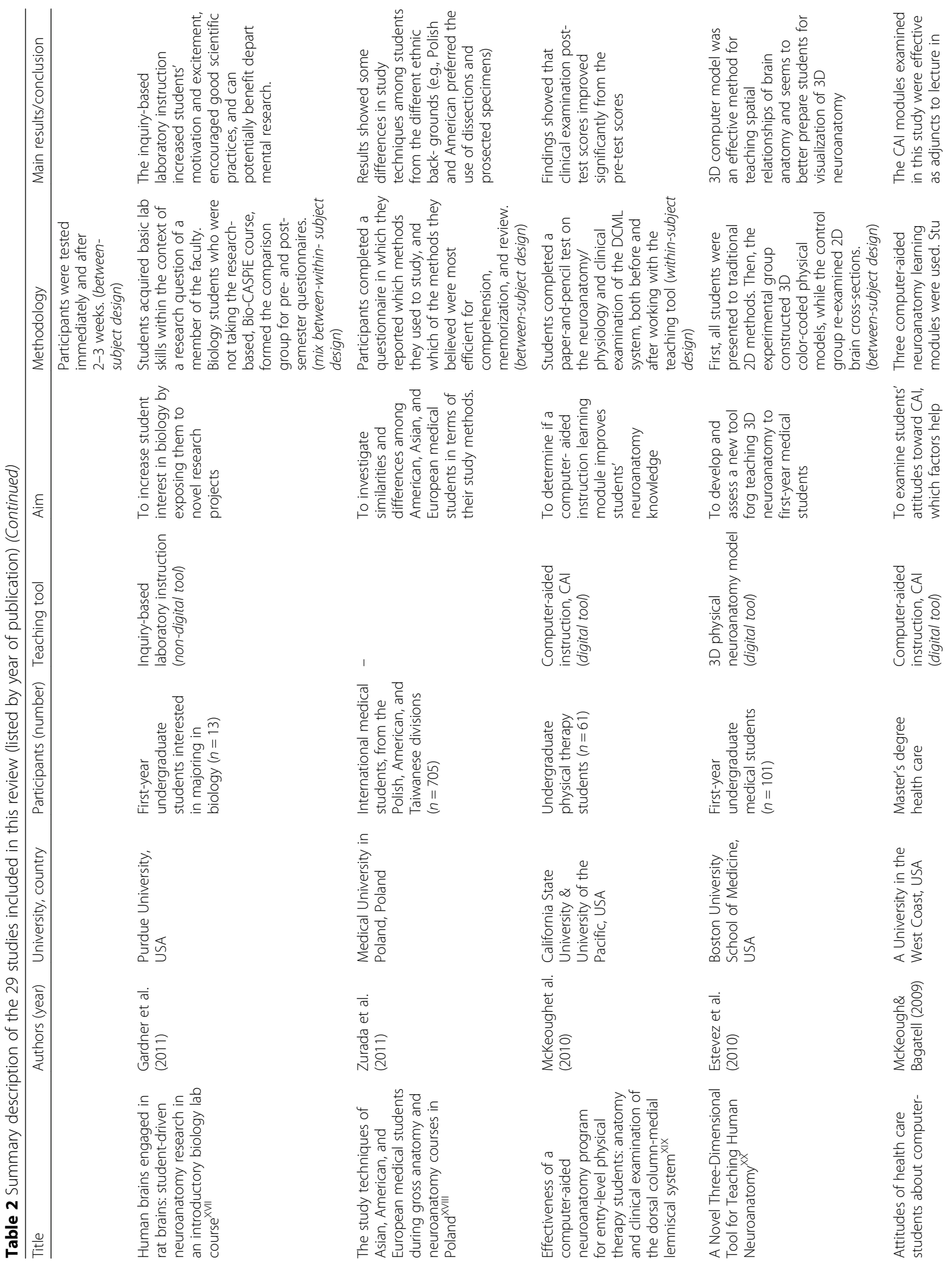




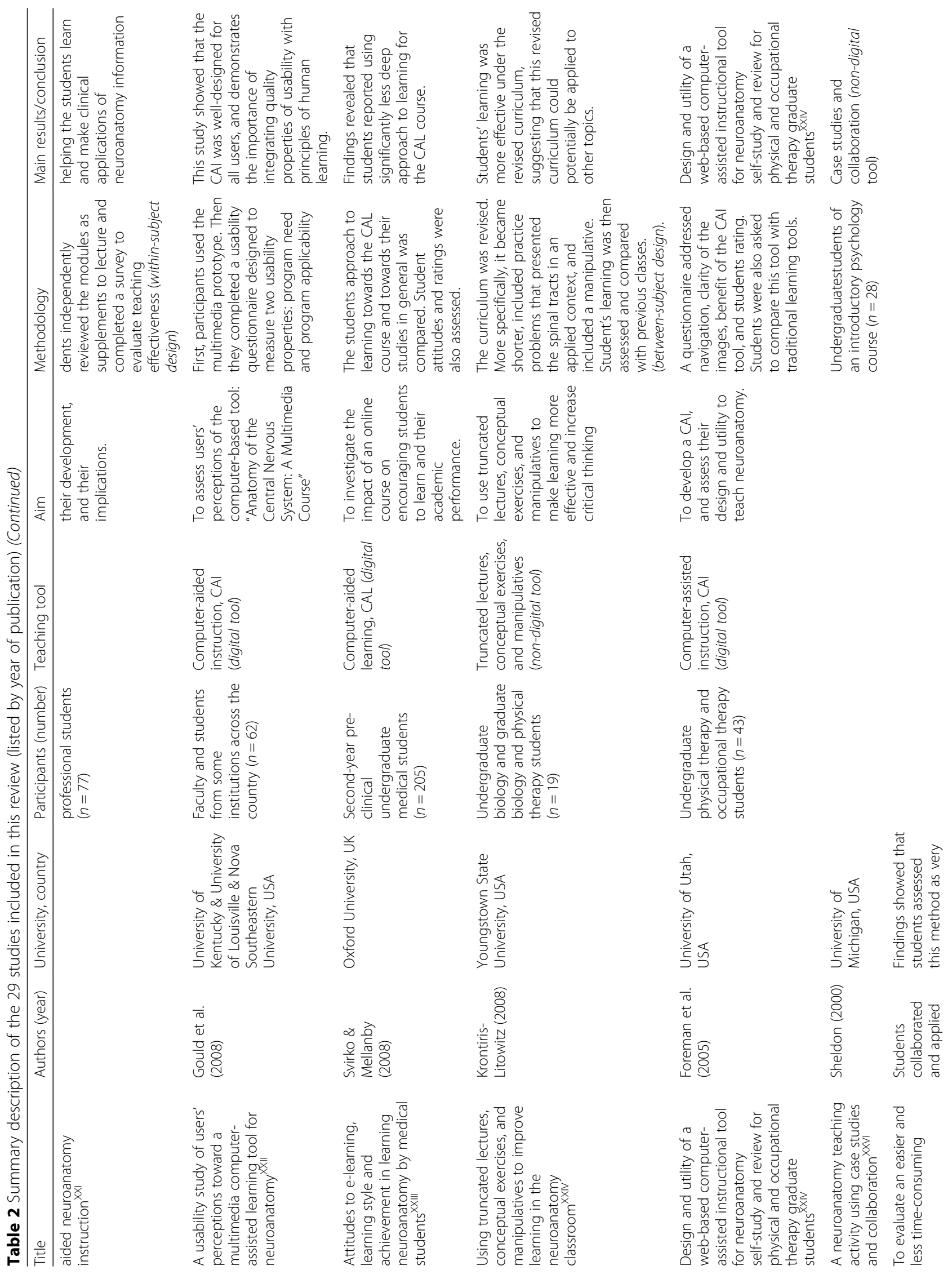




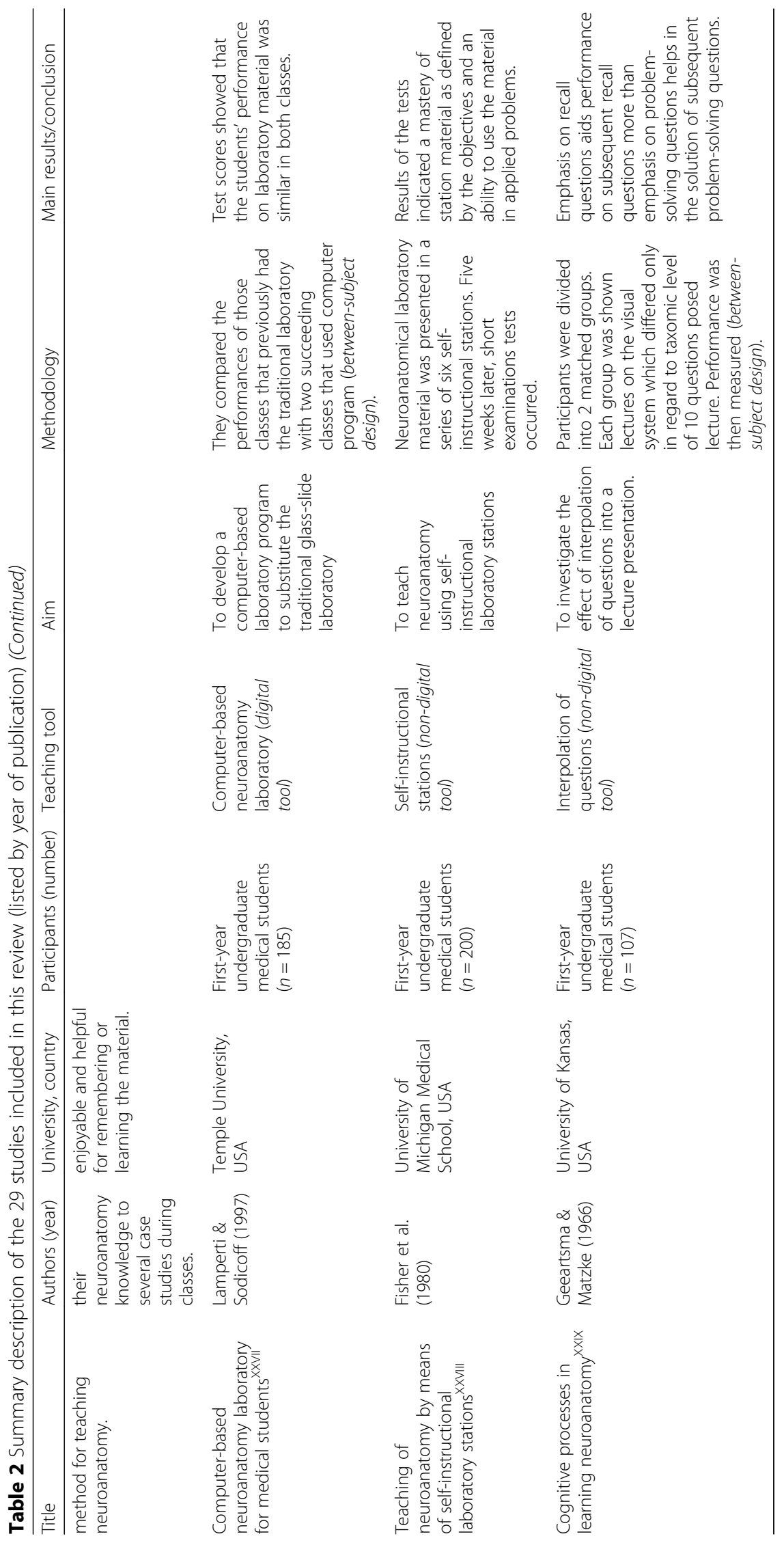


navigation and benefits, clarity of the images, and by requesting them to compare these tools to traditional ones. Results showed that most of the students agreed that the computer-based tool was easy to navigate and overall beneficial, educational in structure identification and had clear images, and somewhat better than traditional learning tools.

Only one study [26] assessed the perception of both students and faculty members with a computer-based tool. Analysis of the results supported the research hypotheses that the prototype was well-designed for different types of users in various educational contexts, and that would be useful as a neuroanatomy review tool for health-professions students.

The studies mentioned above suggested that computerbased tools seem to be effective in teaching neuroanatomy. Lamperti and Sodicoff [27] compared students' performance between those classes that previously had the traditional anatomy laboratory with two succeeding classes that used the computer-based laboratory. When assessing the total performances, results showed no statistically significant differences in the average grades for classes during the 2 years prior to and 2 years following the introduction of computers in the course. However, Svirko and Mellanby [28] compared the students' approach to learning for a computer-based course in Neuroanatomy with that for their studies in general. Students reported lower deep approach scores (seeking the meaning of the information being taught) and higher surface approach scores (rote-learning motivated by fear of failure and without integrating current and previous knowledge) for the computer-aided course than for their studies in general. Also, only approximately one quarter of the students agreed or strongly agreed they enjoyed this course.

\section{D computer neuroanatomy tools}

More recently, studies have used three-dimensional (3D) computer graphical models of human brain as a teaching tool in neuroanatomy classes [29-34]. For example, Drapkin et al. [29] compared students' performance when learning through a new 3D program or through traditional methods. They divided the students into two groups: an experimental (3D program) and a control group (traditional). Results showed that scores extracted from questions involving $\mathrm{C}$-shaped internal brain structures were higher for the experimental group, and that these students reported higher confidence levels. Allen et al. [30] also divided the students into two groups, but each group was exposed to two types of teaching resources, presented in a contrabalanced order: 3D new learning module and cadaveric laboratory session. After accessing each teaching resource, participants completed a test. Findings showed that participants who initially learned using the 3D learning module scored significantly better than students who learned using the gross anatomy resources. In addition, scores significantly improved for students who accessed the 3D learning module following exposure to the cadaveric resources. Palomera et al. [31] assessed if students' evaluation of a new 3D computer-based tool depended on their visuospatial skills to establish handle spatial relationships. Findings revealed that students with both high visuospatial ability and low visuospatial ability assigned similar high educational value to this tool.

Naaz et al. [32], Pani et al. [33] and Chariker et al. [34] focused on the learning of whole and sectional neuroanatomy using neuroanatomical 3D computer models. Their findings suggested that: i) explicit graphical demonstration of the spatial relations between 3D whole anatomy and 2D sectional anatomy leads to high longterm retention of sectional neuroanatomy [32]; ii) an integrative learning method, that presents whole and sectional neuroanatomy in alternating trials, increases the students' performance [33]; and iii) instruction of neuroanatomy designed on the basis of substantial transfer of learning from whole to sectional anatomy is an effective method for teaching neuroanatomical structures [34].

\section{Other digital tools}

Only one study used tablet devices (Apple iPads) in neuroanatomy practical sessions to investigate the effectiveness of specific apps in students' perceptions and performance [35]. Results showed that the students considered the apps to be beneficial for learning. In addition, their performance in neuroanatomy-related questions increased after the introduction of the tablet devices.

\section{Non-digital tools}

Regarding the use of non-digital tools, there is a variety of resources that can be used in neuroanatomy classes. In their pioneer work, published in 1966, Geeartsma and Matzke [36] investigated the effect of interpolation of questions into a lecture presentation. Findings revealed that the emphasis on recall questions led to an increase in students' performance on subsequent recall test questions.

Krontiris-Litowitz [37] studied a revised curriculum using truncated lectures, conceptual exercises, manipulatives, and that was shorter. She found that students' learning was more effective under this new curriculum. Whillier \& Lystad [38] also compared units of neuroanatomy for undergraduate students: an intensive mode and a traditional mode. Even though students showed similar levels of satisfaction, grades were lower in the new intense mode. In addition, Whillier \& Lystad [39] compared two other units of neuroanatomy - an old and a restructured unit. Results showed that the increase 
in total face-to-face teaching hours in the restructured unit led to an increase in the students' satisfaction. However, it does not improve their grades.

Sheldon [40], Kennedy [41] and Greenwald and Quitadamo [42] included several case studies during classes and students were expected to collaborate and participate in their discussions. Results showed that students evaluated this method as enjoyable, helpful for remembering or learning the material, commented positively on the class activities and gained more national percentile ranks than students in a conventional neuroanatomy course. Watson [43] used interactive classroom exercises using well-known Renaissance artists' depictions of the brain, and found that these exercises increase the interest of the students in neuroanatomy. Veeramani et al. [44] investigated the impact of another method that also aims to increase students' collaboration and participation in class: a flipped classroom approach. In this method, students are expected to attend the class with basic understanding of the subject to be able to participate and engage in discussions. Findings revealed that most of the participants felt that the work-sheet with questions provided before class allowed them to adquired a deeper understanding of the subject and believed that the resources provided increased their interest to read.

Fisher et al. [45] used neuroanatomy self-instruction laboratory stations to present neuroanatomical laboratory material making the students' more active in their learning process. Test results indicated a mastery of station material and positive students' attitudes. Gardner et al. [46] exposed students to novel research projets into their laboratory experience. Findings showed that working within the context of a research question of a member of the faculty increase students' motivation and excitement, and encouraged good scientific practice. Hall et al. [47] developed and delivered a near-peer programme of study, in which two medical students delivered the teaching to their colleges, aiming them to grow through their similar knowledge base and shared experiences. After a series of seven sessions, students perceived their level of knowledge as being higher.

Pytte and Fienup [48] and Greville et al. [49] used equivalence-based instruction (EBI) as a tool for teaching neuroanatomy to undergraduate students - teaching how physically disparate stimuli are functionally equivalent, or interchangeable. Findings suggested that: i) selection of associations by the teacher can led to the spontaneous emergences of novel associations within a concept or category; and ii) EBI is a useful tool to teach students to read an MRI of the brain and speciflly useful for teaching $\mathrm{C}$-shaped internal brain structures.

Finaly, even though the use of 3D computer models to teach neuroanatomy has been increasing since 2011, 1 year before Estevez et al. [50] developed and assessed a
3D physical tool. Whereas the control group was exposed to 2D brain cross-sections, the experimental group constructed 3D color-coded physical models. Test results showed that the overall quiz scores for the experimental group were significantly higher than the control group. However, only the scores for questions requiring $3 \mathrm{D}$ visualization were significantly higher in the experimental group.

\section{Cross-cultural comparisons}

Zurada et al. [51] investigated similarities and differences in study methods among American, Asian, and European medical students. For that, the authors asked participants to fill a questionnaire reporting the study methods they use to study, and which methods they believed were the most effective in terms of comprehension, memorization, and review. Results revealed differences in the study techniques among students from the different countries. For example, Polish and American tended to prefer the use of dissection and prosected specimens compared to the Taiwanese students.

\section{Discussion}

From searching PubMed, Web of Science, Medline, Current Contents Connect, KCI and Scielo Citation Index databases, 29 studies were identified. Even though the first study was published 50 years ago, more than four-fifths of the studies were published in the last 8 years, evidencing a growing awareness of this thematic over the most recent years. In fact, several modifications in anatomy and, in particular, in neuroanatomy education have been made over the last few decades, and numerous strategies have been recognized to increase the performance of students [52]. The studies emerged from different countries, including United States of America, United Kingdom, Australia, Canada, India, Poland and Spain. This indicates that the interest for the teaching of neuroanatomy is cross-cultural. However, the paper published by Zurada et al. [51] showed that there are some differences in the study methods adopted by medical students from different countries, such as American, Asian, and European.

Concerning the type of participants, medical students are the most studied sample, which is not surprising taking in consideration that, although several changes have occurred in medical curricula worldwide, the anatomic background is still considered a keystone for approaching clinical medicine [53]. Regarding the number of participants, approximately two-thirds used a sample of 100 participants or less, leading to a low average statistical power. This is a concern regarding published literature in this area, as many of the studies found in this review have limitations imposed by sample size. For example, Gardner et al. [46] investigated only 13 students, 
Krontiris-Litowitz [37] 19 students, Watson [43] 27, and Sheldon [40] 28 students. A small statistical power is known to reduce chance of detecting a true effect, as well as to reduce the likelihood that a statistically significant result reflects a true effect [54].

In terms of teaching methods used in the studies included in this review, almost half of them used digital tools, such as computer-based tools, 3D computer neuroanatomy models and apps installed in tablets. The majority of the six studies that focused on computerbased neuroanatomy tools showed that: i) it is welldesigned for both students and faculty members; ii) the performance of the students increased after working with the learning model; and iii) the students had positive attitudes towards these tools. However, the two remaining studies found that there were no statistically significant differences in the average grades of the students after the introduction of computers in the course, and that students reported lower deep approach scores for the computer-aided course than for their studies in general. These results suggest that even though the computer-based tools seem to be effective in teaching neuroanatomy in certain contexts, this assumption cannot be generalized without further research.

Since 2014, half of the studies focused on 3D computer-based tools, highlighting a growing interest in exploring 3D models on learning of neuroanatomy. Overall, these studies revealed that this digital tool is an effective method for teaching neuroanatomical structures. Findings also showed that students assigned a high educational value to this tool. These results are somewhat inconsistent with those from Azer and Azer [55] who concluded in their review that there is no evidence that the use of 3D models is superior to traditional tools for teaching anatomy. It is possible that the structure of the brain have some particularities that require more the use of the students' visual-spatial abilities than other anatomical structures of the body. Therefore, the use of $3 \mathrm{D}$ tools, by facilitating the mental rotation and manipulation of the brain structures, may facilitate the learning of neuroanatomy.

The non-digital tools include a variety of resources used in neuroanatomy classes.

Findings revealed that the following strategies led to an increase in students' performance and positive attitudes: i) emphasis on recall questions; ii) use of case studies; iii) inclusion during class of truncated lectures, conceptual exercises, and manipulatives; iv) practice of exercises using well-known Renaissance artists' depictions of the brain; v) adoption of the flipped classroom approach; vi) use of neuroanatomy self-instruction laboratory stations; vii) inclusion of novel research projets into the laboratory experience; viii) near-peer programmes; ix) EBI; and $\mathrm{x}$ ) 3D physical models. The increase in total face-to-face teaching opportunities was shown to increase students' satisfaction but not their grades, and teaching neuroanatomy in an intense mode was shown to lower students' grades compared to a traditional mode.

\section{Limitations}

Even though a rigorous approach was adopted to undergo this systematic literature review, our study presents some limitations. First, we restricted our search to six databases: PubMed, Web of Science, Medline, Current Contents Connect, KCI and Scielo Citation Index databases. Thus, it is possible that some studies addressing our aim could be found if searches in other databases were conducted. Second, in our search, four sets of keywords were used, combining "neuroanatomy" with "education", "teaching", "learning" and "student"". It is also possible that some studies may focus on neuroanatomy teaching tools but use other terminology to describe them. Third, this review included only papers written in English, and therefore 12 out of 117 studies were eliminated. Some of those papers written in languages other than English may address the aim of our study, and we did not consider them. Fourth, even though all studies were carefully reviewed independently by two readers, and all data collected was confirmed by a third reader, data may been biased by the subjectivity of the readers.

\section{Conclusions}

Our work highlights the progressive interest in the study of neuroanatomy teaching tools over the last 8 years, as evidenced from the number of publications. The view of the different strategies to teach neuroanatomy, may provide guidelines for curricular improvements in this complex area of medical education.

\section{Abbreviations}

3D: Three-dimensional; CAl: Computer-aided instruction; CAL: Computeraided learning; DCML: Dorsal column-medial lemniscal; EBI: Equivalencebased instruction; IBCC: Inquiry-based clinical case

\section{Availability of data and materials}

Not applicable - all papers reviewed as part of the review can be sourced online.

\section{Authors' contributions}

M.F conceived and designed the project. M.A. and J.A. were involved in developing the data analysis matrix and in the selection of the articles. All authors analysed the articles. M.A. drafted the manuscript. M.F. made a critical revision of manuscript. All authors have read and approved the final version of this manuscript.

Ethics approval and consent to participate Not applicable.

Competing interests

The authors declare that they have no competing interests. 


\section{Publisher's Note}

Springer Nature remains neutral with regard to jurisdictional claims in published maps and institutional affiliations.

\section{Author details \\ 'Department of Biomedicine, Unit of Anatomy, Faculty of Medicine of the University of Porto, Al. Prof. Hernâni Monteiro, 4200 - 319, Porto, Portugal. ${ }^{2}$ Division of Neuroradiology, Department of Radiology, Portuguese Institute of Oncology, Porto, Portugal. ${ }^{3}$ Psychology School, University of Minho, Campus de Gualtar, 4710-057 Braga, Portugal. ${ }^{4}$ Department of Public Health, Forensic Sciences and Medical Education, Faculty of Medicine of the University of Porto, Al. Prof. Hernâni Monteiro, 4200 - 319, Porto, Portugal.}

Received: 6 September 2017 Accepted: 25 April 2018

Published online: 03 May 2018

\section{References}

1. Verhoeven BH, Verwijnen GM, Scherpbier AJJA, Van Der Vleuten CPM. Growth of medical knowledge. Med Educ. 2002;36:711-7.

2. Dumitrascu DI. Andreas Vesalius şi anatomia umană în Renaştere. [Vesalius and human anatomy in the renaissance]. Rev Med Romana. 2014;61(4):332-6.

3. Ghosh SK. Human cadaveric dissection: a historical account from ancient Greece to the modern era. Anat Cell Biol. 2015;48(3):153-69.

4. Flexner A. Medical education in the United States and Canada: a report to the Carnegie Foundation for the Advancement for Teaching. New York: The Carnegie Foundation for the Advancement of Teaching; 1910. Available from: http://www. carnegiefoundation.org/files/elibrary/Carnegie

5. Turney BW. Anatomy in a modern medical curriculum. Ann R Coll Surg Engl. 2007;89(2):104-7.

6. Bergman EM, Prince KJ, Drukker J, van der Vleuten CP, Scherpbier AJ. How much anatomy is enough? Anat Sci Educ. 2008;1:184-8.

7. Drake RL, McBride JM, Lachman N, Pawlina W. Medical education in the anatomical sciences: the winds of change continue to blow. Anat Sci Educ. 2009;2:253-9.

8. Irby DM, Cooke M, O'Brien BC. Calls for reform of medical education by the Carnegie Foundation for the Advancement of Teaching: 1910 and 2010. Acad Med. 2010:85:220-7.

9. Muller JH, Jain S, Loeser H, Irby DM. Lessons learned about integrating a medical school curriculum: perceptions of students, faculty and curriculum leaders. Med Educ. 2008;42:778-85.

10. Louw G, Eizenberg N, Carmichael SW. The place of anatomy in medical education: AMEE guide no 41. Med Teach. 2009;31:373-86.

11. Wilkerson L, Stevens CM, Krasne S. No content without context: integrating basic, clinical, and social sciences in a preclerkship curriculum. Med Teach. 2009;31:812-21.

12. Ghosh S, Pandya HV. Implementation of Integrated Learning Program in neurosciences during first year of traditional medical course: Perception of students and faculty. BMC Med Educ. 2008;24:8-44.

13. Drake RL. A retrospective and prospective look at medical education in the United States: trends shaping anatomical sciences education. J Anat. 2014; 224:256-60.

14. Halliday N, O'Donoghue D, Klump KE, Thompson B. Human structure in six and one-half weeks: one approach to providing foundational anatomical competency in an era of compressed medical school anatomy curricula. Anat Sci Educ. 2015;8(2):149-57.

15. Papa V, Vaccarezza M. Teaching anatomy in the XXI century: new aspects and pitfalls. Sci World J. 2013;7(2013):310348.

16. Craig S, Tait N, Boers D, McAndrew D. Review of anatomy education in Australian and New Zealand medical schools. ANZ J Surg. 2010;80:212-6.

17. Sugand $K$, Abrahams $P$, Khurana A. The anatomy of anatomy: a review for its modernization. Anat Sci Educ. 2010;3:83-93.

18. Brooks WS, Woodley KT, Jackson JR, Hoesley CJ. Integration of gross anatomy in an organ system-based medical curriculum: strategies and challenges. Anat Sci Educ. 2015;8(3):266-74.

19. McLachlan JC, Bligh J, Bradley P, Searle J. Teaching anatomy without cadavers. Med Educ. 2004;38(4):418-24.

20. Giles J. Clinical neuroscience attachments: a student's view of 'neurophobia'. Clin Teach. 2010;7(1):9-13.

21. Jozefowicz RF. Neurophobia: the fear of neurology among medical students. Arch Neurol. 1994;51(4):328-9.
22. Moxham B, McHanwell S, Plaisant O, Pais D. A core syllabus for the teaching of neuroanatomy to medical students. Clin Anat. 2015;28(6):706-16.

23. McKeough DM, Bagatell N. Attitudes of health care students about computeraided neuroanatomy instruction. J Allied Health. 2009:38(4):189-95.

24. McKeough DM, Mattern-Baxter K, Barakatt E. Effectiveness of a computeraided neuroanatomy program for entry-level physical therapy students: anatomy and clinical examination of the dorsal column-medial lemniscal system. J Allied Health. 2010;39(3):156-64.

25. Foreman KB, Morton DA, Musolino GM, Albertine KH. Design and utility of a web-based computer-assisted instructional tool for neuroanatomy self-study and review for physical and occupational therapy graduate students. Anat Rec (Part B: New Anat). 2005;285B(1):26-31.

26. Gould DJ, Terrell MA, Fleming J. A usability study of users' perceptions toward a multimedia computer-assisted learning tool for neuroanatomy. Anat Sci Educ. 2008;1(4):175-83.

27. Lamperti A, Sodicoff M. Computer-based neuroanatomy laboratory for medical students. Anat Re. 1997;249(3):422-8.

28. Svirko E, Mellanby J. Attitudes to e-learning, learning style and achievement in learning neuroanatomy by medical students. Med Teach. 2008:30(9-10):e219-27.

29. Drapkin ZA, Lindgren KA, Lopez MJ, Stabio ME. Development and assessment of a new 3D neuroanatomy teaching tool for MRI training. Anat Sci Educ. 2015;8(6):502-9.

30. Allen LK, Eagleson R, de Ribaupierre S. Evaluation of an online threedimensional interactive resource for undergraduate neuroanatomy education. Stud Health Technol Inform. 2016;220:5-8.

31. Palomera PR, Méndez JAJ, Galino AP. Enhancing neuroanatomy education using computer-based instructional material. Comput Hum Behav. 2014;31: 446-52.

32. Naaz F, Chariker JH, Pani JR. Computer-based learning: graphical integration of whole and sectional neuroanatomy improves long-term retention. Cogn Instr. 2014;32(1):44-64

33. Pani JR, Chariker JH, Naaz F. Computer-based learning: interleaving whole and sectional representation of neuroanatomy. Anat Sci Educ. 2013;6(1):11-8.

34. Chariker JH, Naaz F, Pani JR. Computer-based learning of neuroanatomy: a longitudinal study of learning, transfer, and retention. J Educ Psychol. 2011; 103(1):19-31.

35. Morris NP, Lambe J, Cicconet J, Swinnerton B. Mobile technology: students perceived benefits of apps for learning neuroanatomy. J Comp Assisted Learning. 2016;32(5):430-42.

36. Geeartsma RH, Matzke HA. Cognitive processes in learning neuroanatomy. J Med Educ. 1966;41(7):690-6.

37. Krontiris-Litowitz J. Using truncated lectures, conceptual exercises, and manipulatives to improve learning in the neuroanatomy classroom. Adv Physiol Educ. 2008;32(2):152-6.

38. Whillier S, Lystad RP. Intensive mode delivery of a neuroanatomy unit: lowe final grades but higher student satisfaction. Anat Sci Educ. 2013;6(5):286-93.

39. Whillier S, Lystad RP. The effect of face-to-face teaching on student knowledge and satisfaction in an undergraduate neuroanatomy course. Anat Sci Educ. 2013:6(4):239-45.

40. Sheldon JP. A neuroanatomy teaching activity using case studies and collaboration. Teach Psychol. 2000;27(2):126-8.

41. Kennedy S. Using case studies as a semester-long tool to teach neuroanatomy and structure-function relationships to undergraduates. J Undergrad Neurosci Educ. 2013;12(1):A18-22.

42. Greenwald RR, Quitadamo IJ. A mind of their own: using inquiry-based teaching to build critical thinking skills and intellectual engagement in an undergraduate neuroanatomy course. J Undergrad Neurosci Educ. 2014; 12(2):A100-6.

43. Watson TD. Da Vinci coding? Using renaissance artists' depictions of the brain to engage student interest in neuroanatomy. J Undergrad Neurosci Educ. 2013;11(2):A174-7.

44. Veeramani R, Madhugirl V, Chand P. Perception of MBBS students to "flipped class room" approach in neuroanatomy module. Anat Cell Biol. 2015:48(2):138-43.

45. Fisher LJ, Davis WK, Hitch EJ, Barr PA. Teaching of neuroanatomy by means of self-instructional laboratory stations. Med Educ. 1980;14(2):119-23.

46. Gardner SM, Adedokun OA, Weaver GC, Bartlett EL. Human brains engaged in rat brains: student-driven neuroanatomy research in an introductory biology lab course. J Undergrad Neurosci Educ. 2011;10(1):A24-36.

47. Hall S, Lewis M, Border S, Powell M. Near-peer teaching in clinical neuroanatomy. Clin Teach. 2013;10(4):230-5. 
48. Pytte $\mathrm{CL}$, Fienup DM. Using equivalence-based instruction to increase efficiency in teaching neuroanatomy. J Undergrad Neurosci Educ. 2012; 10(2):A125-31.

49. Greville WJ, Dymond S, Newton PM. The student experience of applied equivalence-based instruction for neuroanatomy teaching. J Educ Eval Health Prof. 2016;13:13-32.

50. Estevez ME, Lindgren KA, Bergethon PR. A novel three-dimensional tool for teaching human neuroanatomy. Anat Sci Educ. 2010;3(6):309-17.

51. Zurada A, Gielecki JS, Osman N, Tubbs RS, Loukas M, Zurada-Zielińska A, Bedi N, Nowak D. The study techniques of Asian, American, and European medical students during gross anatomy and neuroanatomy courses in Poland. Surg Radiol Anat. 2011;33:161-9.

52. Rizzolo LJ, Rando WC, O'Brien MK, Haims AH, Stewart WB. Design, implementation, and evaluation of an innovative anatomy course. Anat Sci Educ. 2010:3:109-20.

53. McLachlan JC, Patten D. Anatomy teaching: ghosts of the past, present and future. Med Educ. 2006;40(3):243-53.

54. Button KS, loannidis JP, Mokrysz C, Nosek BA, Flint J, Robinson ES, Munafò MR. Power failure: why small sample size undermines the reliability of neuroscience. Nat Rev Neurosci. 2013;14(5):365-76.

55. Azer SA. 3D anatomy models and impact on learning: a review of the quality of the literature. Health Prof Educ. 2016;2:80-98.

Ready to submit your research? Choose BMC and benefit from:

- fast, convenient online submission

- thorough peer review by experienced researchers in your field

- rapid publication on acceptance

- support for research data, including large and complex data types

- gold Open Access which fosters wider collaboration and increased citations

- maximum visibility for your research: over $100 \mathrm{M}$ website views per year

At BMC, research is always in progress.

Learn more biomedcentral.com/submissions 